The "Encyclopædia Britannica"-The Nile

THE volume of the Nile is made a thousand times greater than the truth in the new "Encyclopredia," vol. vii. p. 706, art. Egypt, by an error copied from the last edition. The same mistake occurs in Rawlinson's "Herodotus," vol. ii. p. 7, Note GW. ; in the Geographical Society's Fournal, vol. xix.; in Fullarton's Gazelteer, and probably elsewhere, and some fables have been founded on it.

I observed the error myself some years ago, after being perplexed by it in some rainfall estimates, and mentioned it to the late Sir Gardner Wilkinson, who intended to have it corrected; but there has been no fresh edition of the "Herodotus," and it has escaped revision in the "Encyclopædia." As it illustrates a special danger, easily overlooked, in copying French figures, it deserves perhaps a few lines in NATURE to put it right.

In English notation we mark decimals with a point, and use commas to divide periods; but the French generally use comamas to mark off decimals. The authority for the volume of the Nile is Linant's measurement, given by Clot Bey in the "Apercu general sur l'Egypte," tome i., pp. 40, 4I, and the figures are given as follows, in cubic metres of water discharged into the Mediterranean at full flood in twenty-four hours :-

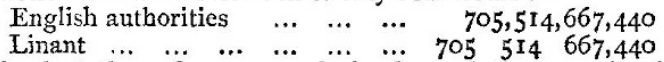

The last three figures are decimals, and the quantity is in millions, not in thousand millions.

ALBerT J. MOTT

December 14

\section{Lunar Rings}

ACCORDING to your suggestion I have followed up my experiments with lunar light on bromo-gelatine plates, and at midnight on November 28 , for the third time at full moon period I

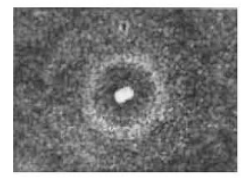

obtained on one plate three well-defined rings round the photographic image of the moon with $I$ minute, $1 \frac{1}{2}$ minute, and 2 minutes' exposure.

The I minute exposure is fainter than the above woodcut, the I $\frac{1}{2}$ minute the same in density, and the 2 minutes' exposure is denser and more defined; while six consecutive nightly observations previous to the 28 th failed to give any vinculum or indication of refraction of light.

One of the six taken on the night of November 24 with two hours' continuous exposure gave a bright clean well-defined line $2 \frac{1}{2}$ inches long, gapped here and there by passing clouds, but not the slightest indication of blurr or dispersion was shown on the brightest parts of the line.

Whether the cause which produces these rings at full moon phase only, depends upon the greater effulgence of lunar reflection at that particular time; whether it is cosmical or atmospheric in its nature, or optical or chemical, there can be no doubt that there is refraction of the lunar light; the existence of a dark space between two luminous (or more correctly speaking actinised regions) as manifested by the above annular periodical impressions is a clear indication of the dispersion of light, but how, why, or where the decomposition takes place is not so obvions.

Sunderland, December 5

GEORGE BERWICK

\section{Stag's Horns}

IT is well known to be the universal belief in the Highlands that stags eat the horns they shed, and every gillie will tell you that no one ever picked up a horn. Can any of your readers inform me what really becomes of them?

There must be abundant opportunities of observing the whole process in places like Windsor Park, where red deer are kept in a domesticated state.

G. W. H.

\section{ON A NEW COPYING PROCESS}

$A$ VERY elegant process has recently been introduced into this country for copying and multiplying letters and documents. It is known by various names, according to the etymological skill of the makers. One calls it a "hektograph," another less pardonably calls it the "centograph," while yet another, to bridge the gap between ancient Greek and modern English, styles it the "printograph." But whether it is introduced by these names, or the polygraph, the compo-lithograph, or the velocograph, the principle is the same; though the details are slightly varied in each case. A slab of gelatinous material in a shallow tin tray forms the type. The letter is written with a special ink on any kind of paper, and when dry is placed face downwards upon the jelly, and allowed to remain a minute or more. On removal it is found that the greater part of the ink has been left behind on the jelly. It is only necessary to place pieces of paper on the latter, and on their removal they are found to be perfect fac similes of the original copy. The number of copies obtainable varies with the ink, the most potent being aniline violet, such as Poirrier's. With this a hundred copies may be produced. Others, such as Bleu de Lyon, Bismarck brown, or Roseine, ${ }^{1}$ yield forty to fifty. It was with a view to determine the principles which govern this beautiful process, that I made an examination of the subject. The slab consists of gelatin and glycerine, with carbolic or salicylic acid to prevent fungoid growth, and in the "chromograph" a quantity of barium sulphate is added, which gives the slab a white, enamel-like appearance.

If a hot, strong solution of gelatin in water be prepared, ${ }^{2}$ and then a certain quantity of glycerine stirred in, the whole mass will become solid in cooling. This might at first sight appear to be a solution of gelatin in water and glycerine; but such is not the case, the gelatin being quite insoluble in glycerine. When the aqueous solution solidifies, the gelatin still retains the water, but the large quantity of glycerine being dispersed through the mass, makes the whole into what is practically a very fine gelatin sponge containing glycerine in its pores.

The moisture-loving nature of the glycerine prevents the "sponge" from getting dry, while the insolubility of the gelatin in the glycerine prevents its becoming liquid. When the copy is placed on the jelly, the glycerine comes out to meet the ink, for which it has an intense liking. All the suitable inks are freely soluble in glycerine. Some, too, contain acetic acid either in the free state or in combination with bases as in rosaniline acetate. The acetic acid exerts a solvent action on the gelatin, so that it will be found that after taking off some impressions with an acetic acid ink, as the "multiplex," the jelly will be etched wherever the ink has come into contact with it. As long as any of the ink remains on the jelly, the glycerine will come out of the pores to keep it moist, but when the whole of the ink has been removed the flow of glycerine ceases, and the parts become quite dry. If the ink is not entirely removed by taking a sufficient number of impressions, and the jelly left, after a lapse of twentyfour hours the remaining ink will be absorbed by the jelly. It is necessary, therefore, that the copies should be taken off as soon as possible, so as to avoid the defect caused by the spreading of the ink.

Most of the makers suggest, that directly the slab is done with, the type should be washed off. The hektograph and most others require that the water should be warm, but the finely divided barium sulphate in the chromograph, renders the surface less tenacious, and the impression may be removed with cold water.

Where practicable, it is better in all cases to leave the slab for twenty-four hours, when the old impression will be quite absorbed, and not interfere with a new one.

This gelatin copying process has been received with so

I A very pctent and easily prepared ink which will yield a hundred copies, may be made by dissolving rosanilne in a cold-saturated solution of oxalic acid. It must be allowed to dry spontaneously.

$4 \mathrm{cz}$. gelatin dissolved in $6 \mathrm{cz}$. water, and $20 \mathrm{oz}$. glycerine, sp. gr. $\mathrm{r}_{2} 6$, previously warmed, stirred in. Any air bubbles in the gelatin are rem oved before the addition of the glycerine. A cheaper compound which answers equally well, but is rather darker, ccnsists of Scotch glue $6 \mathrm{oz}$, water $8 \mathrm{oz}$. glycerine 2002 . These quantities make a slab to $\times 13 \times 1$ 
much favour by the public, that it shows there is a great want for some rapid means of getting a limited number of copies of letters, \&c. ; and seeing that any number of colours may be used in the original drawing, Mr. Norman Lockyer has suggested that it would be of much use in laboratories, for the multiplication of original sketches of biological specimens, and even for spectra charts, and so save much of the time spent in making duplicate copies. The gelatin slab cannot be said to be perfect, as it is liable to be affected by atmospheric changes; but, bearing in mind the fact that the whole is simply a sponge filled with a compound capable of liquefying certain inks, it is reasonable to hope and expect that chromography is only the pioneer of a process, which shall possess all its advantages and none of its defects.

R. H. RIDOUT

\section{THE ANIMAL HEAT OF FISHES}

$T^{H E}$ $\mathrm{E}$ belief that fishes are cold-blooded, that is, that they take on the temperature of the water which surrounds them, with no power to resist it, and that they develop little or no animal heat themselves, is still held by many even scientific observers, This belief is based partly upon the well-authenticated fact that fishes have been frozen and thawed again into life; partly upon the statements of many travellers who have found them living in water of a very high temperature (Humboldt and Bonpland recording the highest, $210^{\circ} \mathrm{F}$.); and further, that a thermometer inserted into the rectum of some living fish freshly drawn from the water has been repeatedly found to indicate temperature corresponding very closely to that of the water itself.

During the past summer, and in connection with the operations of the U.S. Fish Commission at Provincetown, Mass., Surgeon J. H. Kidder, of the U.S. Navy, was detailed to make some systematic observations upon the subject of fish-temperatures with a view to setting the question upon a secure basis of actual experiment. Thermometers were made expressly for the purpose by Mr. John Taglialne, of New York, of unusual delicacy, registering about $10^{\circ} \mathrm{F}$. each, and recording fifths of a degree. These were used in connection with Negretti and Zambra's deep-sea thermometers, and all the instruments were deduced to a single standard by frequent comparisons, so as to insure relative accuracy. The fish were taken with a line, and their temperatures observed at once, care being taken that no considerable change in temperature occurred during the time consumed in bringing the fish to the surface. The observed temperatures were then compared with that of the water as recorded by a Negretti-Zambra thermometer sunk to about the depth from which the fishes were taken. The first observations, made by inserting the thermometer into the rectum of the fish, agreed with the generally-received opinion, showing but little higher temperature than that of the surrounding water.

The mode of experiment was then somewhat modified. Considering the fact that the intestinal canal of a fish is in close contact with the thin and scarcely vascular walls of the abdomen, which is surrounded by the water in which the animal swims; and, further, that the arterial blood comes from the gills, where it has been spread out as thinly as possible and brought into the closest contact with the surrounding water-a process well calculated to cool it quickly to the same temperature-it follows that neither the interior of the rectum nor the arterial blood would appear to have the same value as representing the body-temperature in fishes that those parts possess in mammals and birds. It is rather in the venous circulation and the branchial artery that we should seek for the heat which must certainly be developed in the chemical processes of nutrition and waste, and in connection with active muscular movements. In the remaining experiments of the series-about ninety in number-the fish was therefore opened at once, and the bulb of the thermometer inserted into the cavity of the heart, or branchial artery, with the results indicated in the following table, which shows the averages :-

\begin{tabular}{|c|c|c|c|c|}
\hline Fish. & $\begin{array}{l}\text { Temp. of } \\
\text { surround- } \\
\text { ing water. }\end{array}$ & Rectum. & $\begin{array}{l}\text { Venous } \\
\text { blood. }\end{array}$ & Remarks. \\
\hline 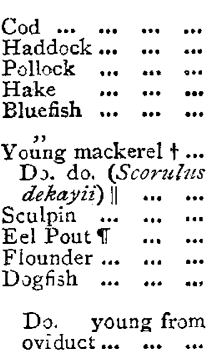 & 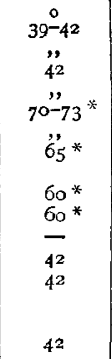 & $\begin{array}{r}0 \\
+0.98 \\
+1.30 \\
+2.40 \\
+2.40 \\
+0.25 \\
+0.50 \\
+4.10 \\
+\overline{0} \\
+30 \\
+3.00 \\
+4.40\end{array}$ & 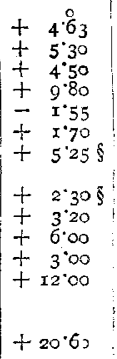 & $\begin{array}{l}\text { Oriducts contained } \\
\text { mature young. }\end{array}$ \\
\hline
\end{tabular}

It appears from these experiments that fishes do develop a measurable quantity of animal heat, which is more apparent during the spawning season, and much greater in elasmobranchs (as is to be expected from their more perfect digestive and assimilative apparatus) than in other fishes. It also appears that the measure of this animal heat is to be sought in the venous blood, and not in the intestinal canal or arterial blood.

The limits of this preliminary note will not permit us to go into an enumeration of the difficulties of observation or the measures taken to guard against the errors likely to attend them. Nor is the number of observations (ninety-five in all) sufficient to warrant the offering of these figures as a final statement of the degree of animal heat presented by the several fishes observed. All that can be said to be proved so far is the fact that fishes do manifest animal heat, and in considerable quantities, sufficient to warm again, to the extent of from $3^{\circ}$ to $12^{\circ}$, blood that has been cooled in each circuit to the temperature of the surrounding water. Details will be given in the forthcoming report of the United States Fish Commission.

In the single instance of a lower temperature than that of the water, observed in five blue-fish, all taken on the same day, it may be that the individuals experimented on, being taken at the surface, had just come up from a much greater depth and colder stratum of water. There seems to be no conceivable provision by which a fish can maintain a temperature below that of the surrounding water, cooling by evaporation being out of the question. The young dogfish from its mother's oviduct showed a temperature $8^{\circ}$ higher than that of the mother herself, for the obvious reason that its blood, not coming into contact with the water by its gills (the umbilical sac was still attached), was not cooled otherwise than mediately, through the blood of the mother.

\section{NEW MODES OF SHOWING DIFFERENT CHARACTERISTICS OVER SMALL ARCS IN AZIMUTH FROM THE SAME LIGHT- HOUSE APPARATUS}

WHERE a light on a rock or island has to illuminate constantly the whole horizon, the ordinary dioptric fixed apparatus is all that is required. But when, as at

*Surface-swimmers † "Sinkers." $\ddagger$ Stomach, through œsophagus. $\$$ Temperature taken in blood flowing from heart, the crgan being too small to admit the thermometer.

II This rare species, not seen in Massachusetts Bay for thirty years, appeared, young, at Provincetown last summer in considerable numbers.

If Zoarces angzilllaris.
The sign "+ "indicates excess, and " - " deficiency, as compared with temperature of water. 